\title{
Experimental study on an innovative enthalpy recovery technology based on indirect flash evaporative cooling
}

Nie, Jinzhe; Yuan, Shu; Fang, Lei; Zhang, Qunli; Li, Deying

Published in:

Applied Thermal Engineering

Link to article, DOI:

10.1016/j.applthermaleng.2017.09.139

Publication date:

2018

Document Version

Peer reviewed version

Link back to DTU Orbit

Citation (APA):

Nie, J., Yuan, S., Fang, L., Zhang, Q., \& Li, D. (2018). Experimental study on an innovative enthalpy recovery technology based on indirect flash evaporative cooling. Applied Thermal Engineering, 129, 22-30.

https://doi.org/10.1016/j.applthermaleng.2017.09.139

\section{General rights}

Copyright and moral rights for the publications made accessible in the public portal are retained by the authors and/or other copyright owners and it is a condition of accessing publications that users recognise and abide by the legal requirements associated with these rights.

- Users may download and print one copy of any publication from the public portal for the purpose of private study or research.

- You may not further distribute the material or use it for any profit-making activity or commercial gain

- You may freely distribute the URL identifying the publication in the public portal 


\section{Experimental study on an innovative enthalpy recovery}

\section{technology based on indirect flash evaporative cooling}

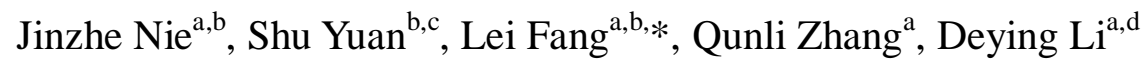

a Beijing Key Lab of Heating, Gas Supply, Ventilating and Air Conditioning Engineering, Beijing University of Civil Engineering and Architecture, Beijing 100044, P.R. China

${ }^{\mathrm{b}}$ International Centre for Indoor Environment and Energy, Department of Civil Engineering, Technical University of Denmark, Kgs. Lyngby 2800, Denmark

${ }^{\mathrm{c}}$ China Academy of Building Research, Beijing 100013, P.R. China

${ }^{\mathrm{d}}$ China Association of Building Energy Efficiency, Beijing 100831, P.R. China

*Corresponding author. E-mail address: fl@byg.dtu.dk

Abstracts:

An indirect flash evaporative cooling enthalpy recovery technology used for building ventilation was proposed based on counter flow plate heat exchanger combing with ultrasonic atomizer. The technology is aimed at enhancing enthalpy recover efficiency and preventing contaminant transfer of heat recovery unit. The principle of the technology is to over saturate indoor exhaust air by ultrasonic atomizing humidification. The evaporation of ultrafine mists cools down indoor exhaust air to its wet-bulb temperature and makes not only sensible heat transfer but also moisture condensed in outdoor supply air to realize total heat recovery. Compared with conventional indirect evaporative cooling, the application of ultrasonic atomizing enhances cooling effect through increasing water mists evaporation area and decreasing heat transfer resistance between exhaust air and supply air. No mass permeation, carrying-over or sorption occurs in this heat exchange process which guarantees no contaminant transfer from exhaust air to supply air. A prototype unit of the proposed technology was developed and tested in climate chambers. Temperatures and humidity ratios at inlets and outlets of the heat recovery unit were measured to investigate and analyze its energy recover efficiencies. The results showed that in hot and humid climate, up to $71 \%$ of total heat recover efficiency could be achieved by the prototype unit, and more than $50 \%$ of the enthalpy recovered was contributed by moisture condensation in the outdoor supply air.

Keywords: Building ventilation; Enthalpy recovery; Indirect evaporative cooling; Flash evaporation; Atomizing humidification. 


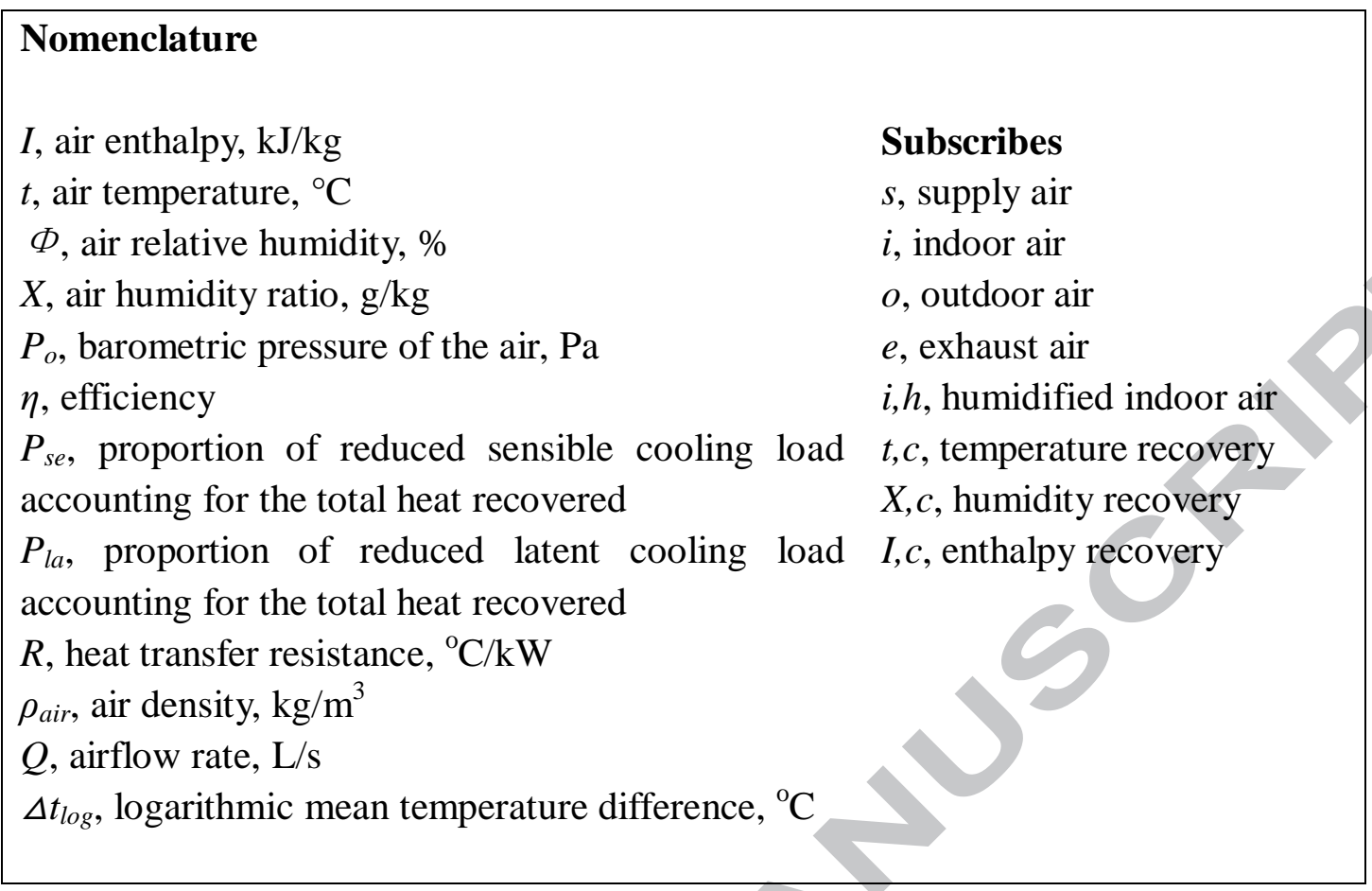

\section{Introduction}

Indoor environment and energy consumption in buildings have drawn broad attentions with the rapid development of new and retrofit buildings. Indoor air quality has been gradually realized to be the important factor which affects occupants' comfort, health and working performance ${ }^{[1]-[4]}$, and plays an important role in indoor environment. Indoor air quality is normally controlled by ventilation which consumes up to $30 \%$ of energy in building $\mathrm{s}^{[5]}$. This proportion can be even higher in future well-insulated and airproof low-energy buildings.

To save energy for building ventilation, heat recovery technologies have been recommended and applied widely. In the study of Zhong and Kang ${ }^{[6]}$, the annual energy consumption of outdoor supply air is evaluated by employing the testing data of climatic parameters in eight selected cities, and an investigation on the choice of heat exchangers for energy savings in buildings was carried out. The applicability of air-to-air heat exchangers in China for different operations was thus given ${ }^{[6]}$. The existing heat recovery units are mainly categorized to be plate sensible heat exchangers, membrane plate enthalpy exchangers, rotary sensible heat exchangers and rotary adsorption enthalpy exchangers. The plate sensible heat exchangers normally use metal foils to separate indoor exhaust air and outdoor supply air and exchange heat between the two airflows. The temperature efficiency of a counter flow plate sensible heat exchanger can reach $90 \%$. However, in hot and humid climate zones where thermal load of a ventilation system is mainly due to dehumidification (the latent load) which accounts for more than $70 \%$ of the total energy for ventilation. This means that the maximum enthalpy efficiency of a plate sensible heat recovery unit (even if its temperature efficiency is $100 \%$ ) applied in such areas is below $30 \%{ }^{[7]}$. 
Total heat exchangers which could recover both sensible and latent heat including polymer membrane and rotary adsorption enthalpy recovery units are regarded as more efficient for energy recovery in hot and humid areas. The membrane plate enthalpy exchangers use polymer membrane to separate indoor exhaust air and outdoor supply air allowing both sensible heat and moisture transfer. The enthalpy efficiency of a polymer membrane foils plate heat exchanger could reach $60 \%-70 \%{ }^{[7]}$. Rotary adsorption enthalpy exchangers use desiccant rotors which are heat exchange wheels coated with sorbent to achieve both sensible heat and moisture recovery. The rotary enthalpy exchangers were found to have the total heat recover efficiency in the range of $50 \%$ to $75 \%{ }^{[8]}$. The heat and moisture transfer through enthalpy exchanger are driven by the differences of temperature and moisture content between outdoor supply air and indoor exhaust air. However, studies showed that either membrane plate or rotary adsorption enthalpy exchanger had the problem of contaminant transfer which reduced ventilation efficiency. In the study of Nie et al. ${ }^{[7]}$, the mass transfer ratios of chemical contaminants through a polymer membrane enthalpy exchanger were tested with tracer gases including toluene, acetone and ammonia. The maximum contaminant transfer ratio was found to be $9 \%$, and the mass transfer was speculated to be caused by solution diffusion, permeation and leakage ${ }^{[7]}$. The mass transfer of pollutants through rotary enthalpy exchanger were tested and analyzed in several studies ${ }^{[9]-[13]}$. In the study conducted by Khoury et al. ${ }^{[9]}$ where $\mathrm{SF}_{6}$ was used as the monitored chemical, a loss of added gas was reported with the proportion of $30 \%$ and explained by adsorption of $\mathrm{SF}_{6}$ on the rotor. The study of Anderson et al. ${ }^{[10]}$ used formaldehyde as tracer gas to investigate the mass transfer in rotary enthalpy exchanger, and found $10 \%$ of formaldehyde could transfer from indoor exhaust air to outdoor supply air even in winter time when outdoor air is colder than indoor air. Pejterson ${ }^{[11]}$ used sensory method to assess a rotary enthalpy recovery unit, and found that the sensory pollution load from a rotary enthalpy exchanger was significant and it might constitute a severe pollution load in ventilation system. Roulet et al. ${ }^{[12]}$ used several VOCs as tracer gases and found that the mass transfer ratios of these VOCs were in the range of $10 \%-30 \%$. Hult et al. ${ }^{[13]}$ conducted field and chamber experiments to investigate the formaldehyde transfer in rotary energy recovery ventilators, and found the formaldehyde transfer ratio was approximately $29 \%$ in field experiments and the ratios were between $10 \%$ and $29 \%$ in chamber tests. Sheng et al. ${ }^{[14]}$ have investigated the VOCs sorption on desiccant rotor with experiment measurements and sensory assessments. The previous studies demonstrated that pollutants will transfer from indoor exhaust air to outdoor supply air through polymer membrane or rotary adsorption enthalpy exchanger. The transfer ratios varied from $9 \%$ to $30 \%$. The mass transfer through enthalpy recovery unit recirculates indoor air pollutants to outdoor supply air and significantly reduces the ventilation efficiency and the indoor air quality.

The above literature reviews showed that existing heat recovery technologies have problems of either low enthalpy efficiency or contaminant transfer. Efforts have been taken on developing new enthalpy recovery ventilator to improve the energy 
efficiency of building ventilation and prevent pollution transfer. A few studies have proposed indirect cooling units which use indoor exhaust air as working air to cool and dehumidify outdoor supply air ${ }^{[15][16]}$. Antonellis et al. ${ }^{[15]}$ combined an indirect evaporative cooler with a cross flow heat exchanger and used it as ventilation and air conditioning unit in data center. Their study proposed a tool to design and predict performance of the indirect evaporative cooling system ${ }^{[15]}$. Cui et al. ${ }^{[16]}$ employed a validated model to investigate the performance of two types of indirect evaporative cooling units in terms of temperature, humidity distribution and cooling effectiveness, and found the units could fulfill $47 \%$ of the cooling load for the outdoor hot and humid air. In the study of Porumb et al. ${ }^{[17]}$, the potential of indirect evaporative cooling (IEC) system reducing the outdoor supply air cooling load in an office building of Cluj-Napoca, Romania was evaluated, and the IEC system could reduce $80 \%$ of the outdoor supply air cooling load. Antonellis et al. ${ }^{[18]}$ analyzed a proposal which used IEC system in data center with theoretical modelling and experimental measurement. The effects of water flow rate, humidification nozzles and working air temperature, humidity and flow rates were investigated, and showed that the IEC performance is influence by nozzles number, nozzles sizes and the water flow rate. The cooling performances of different types of crossflow IEC systems operated in general mode which used indoor exhaust air as working air and regenerative mode which used a portion of outdoor air used as working air were investigated in the study of Kim et al. ${ }^{[19]}$, and the results showed that in the general operation mode, IEC systems exhibited higher sensible cooling performances in terms of wet bulb effectiveness than the regenerative mode. Tejero-gonzález et al. ${ }^{[20]}$ evaluated the influence of constructive parameters on the performance of two indirect evaporative cooler prototypes. Moshari and Heidarinejad ${ }^{[21]}$ theoretically analyzed the regenerative evaporative coolers for sub-wet bulb cooling with cross-and counter-flow configuration. The results showed that in regenerative evaporative cooling unit, the product air temperature decreases as the working air to total inlet air ratio increases. Indirect evaporative cooling has been studied and used in ventilation systems for years, different applicating methods lead to significant different energy recover efficiency.

To further improve the energy efficiency of heat recovery unit and prevent contaminant transfer, an indirect flash evaporative cooling (IFEC) enthalpy recovery technology combing plate heat exchanger with ultrasonic atomizer was proposed in this paper. A prototype unit and a test rig were developed and installed in twin climate chambers. Experimental measurements were then conducted to investigate the energy performance and dynamic operation law of the proposed system. 


\section{Methods}

\section{Principles of IFEC enthalpy recovery technology}

The proposed technology is based on indirect flash evaporative cooling to enhance total heat recover efficiency through moisture evaporating and condensing on each side of a plate heat exchanger. The design of the technology is to add an ultrasonic atomizer on indoor exhaust air side before it enters the plate heat exchanger. The ultrasonic atomizer breaks water into huge amount of ultra-fine water mists and adiabatically humidify the indoor exhaust air. Due to the evaporation of atomized water, the indoor exhaust air is cooled down to its wet-bulb temperature and become over saturated simultaneously. The cooled indoor exhaust air exchanges heat with the incoming outdoor air to decrease the temperature of supply air. Since the atomized mists are more than which are needed to saturate the indoor exhaust air, large quantity of surplus ultra-fine water mists are carried by the air and keep the air over saturated. Inside the heat exchanger, these fine mists will flash evaporate when absorb heat transferred from the outdoor supply air and make the indoor exhaust air at wet-bulb temperature points all through. The cooled indoor exhaust air makes the surface temperature of foils lower than the dew point temperature of outdoor supply air and thus make condensation e.g. dehumidification occur in the outdoor supply air channel. Thus, both sensible and latent heat of the incoming outdoor air could be removed, which is equivalent to recover the total heat of the indoor exhaust air. Unlike the conventional IEC technology, the IFEC utilize the ultrasonic atomizer instead of high-pressure spraying or water drip packing to take the flash evaporation potential of ultrafine mists. Compared to conventional IEC, the flash evaporation of mists in IFEC decrease the heat transfer resistance between indoor exhaust air and outdoor supply air, and increase the mists evaporation area. This make the over saturated indoor exhaust air absorb more heat from the outdoor supply air which lead to a higher temperature drop and more moisture condensed from the outdoor supply air. Since the latent heat recovery is realized by moisture condensation in the outdoor air channel of the plate heat exchanger, the heat recovery process involves only heat transfer without mass transfer, adsorption/desorption or carrying over. Thus, there is no contaminant transfer between the indoor exhaust air and outdoor supply air in the proposed total heat recovery unit.

A prototype unit of the system was designed and developed based on the above principles. The prototype unit included a counter flow sensible heat exchanger with the rated airflow rate of 20L/s, an ultrasonic atomizer, a water supply system and a water collection system. The ultrasonic atomizer was used to break water to fine droplets. The counter flow heat exchanger was used as the medium for heat transfer between indoor exhaust air and outdoor supply air. The water collecting system was designed to collect and reuse the condensed water from the incoming outdoor air channel and the surplus atomized water coagulated in indoor exhaust air channel of 
the heat exchanger. The supply water system was used to provide water for the ultrasonic atomizer. Figure 1 gives the schematic principle of the proposed enthalpy recovery prototype unit.

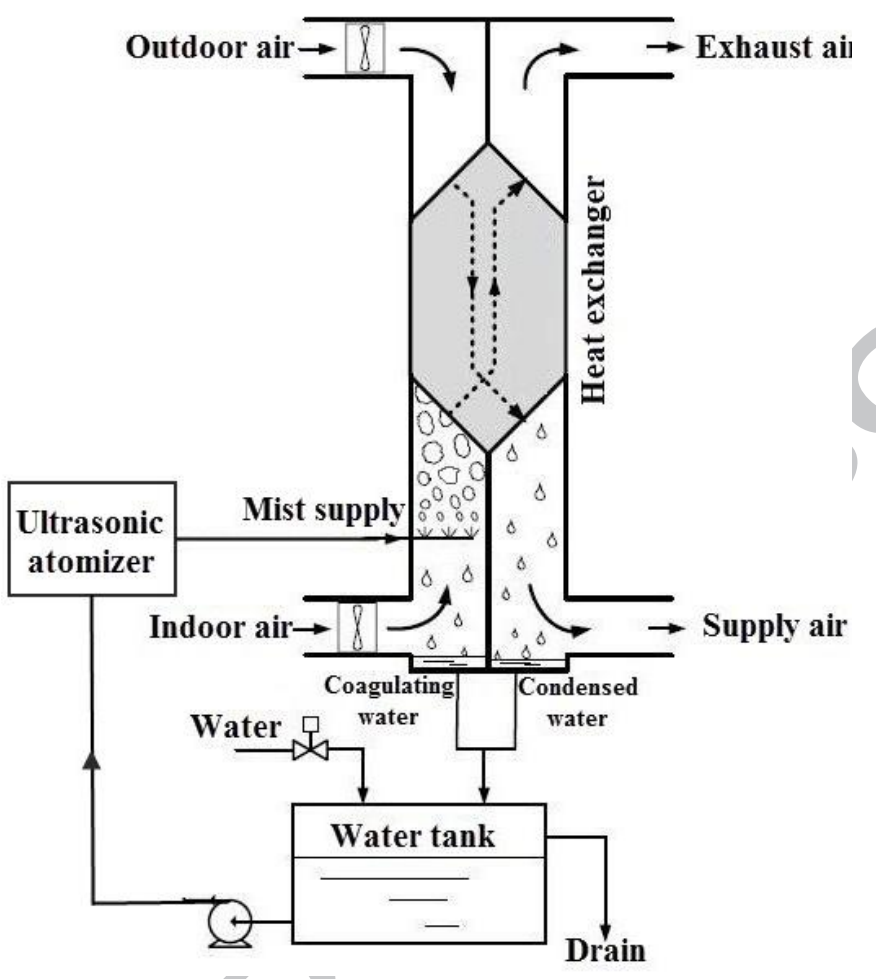

Figure 1. Principle of the proposed total heat recovery unit

\section{Experimental setup}

A test rig for the proposed total heat recovery unit was designed and developed as shown in Figure 2. The test rig included the proposed enthalpy recovery unit, air ducts with supply air and exhaust air fans, airflow control system, temperature and humidity sensors which were installed on the inlets and outlets of the heat exchanger and a data acquisition system to log all the data collected in the experiment.

The experimental setup was developed in twin climate chambers with one chamber simulating outdoor thermal climate and the other simulating air-conditioned indoor thermal climate. The test rig was installed in the climate chamber simulating indoor thermal climate, and the mimic indoor exhaust air was taken directly from the chamber. The outdoor supply air for the total heat recovery unit was taken from the other chamber simulating outdoor climate. Both temperature and humidity ratio of indoor exhaust air and outdoor supply air at the inlets and outlets of the heat exchanger were measured. 


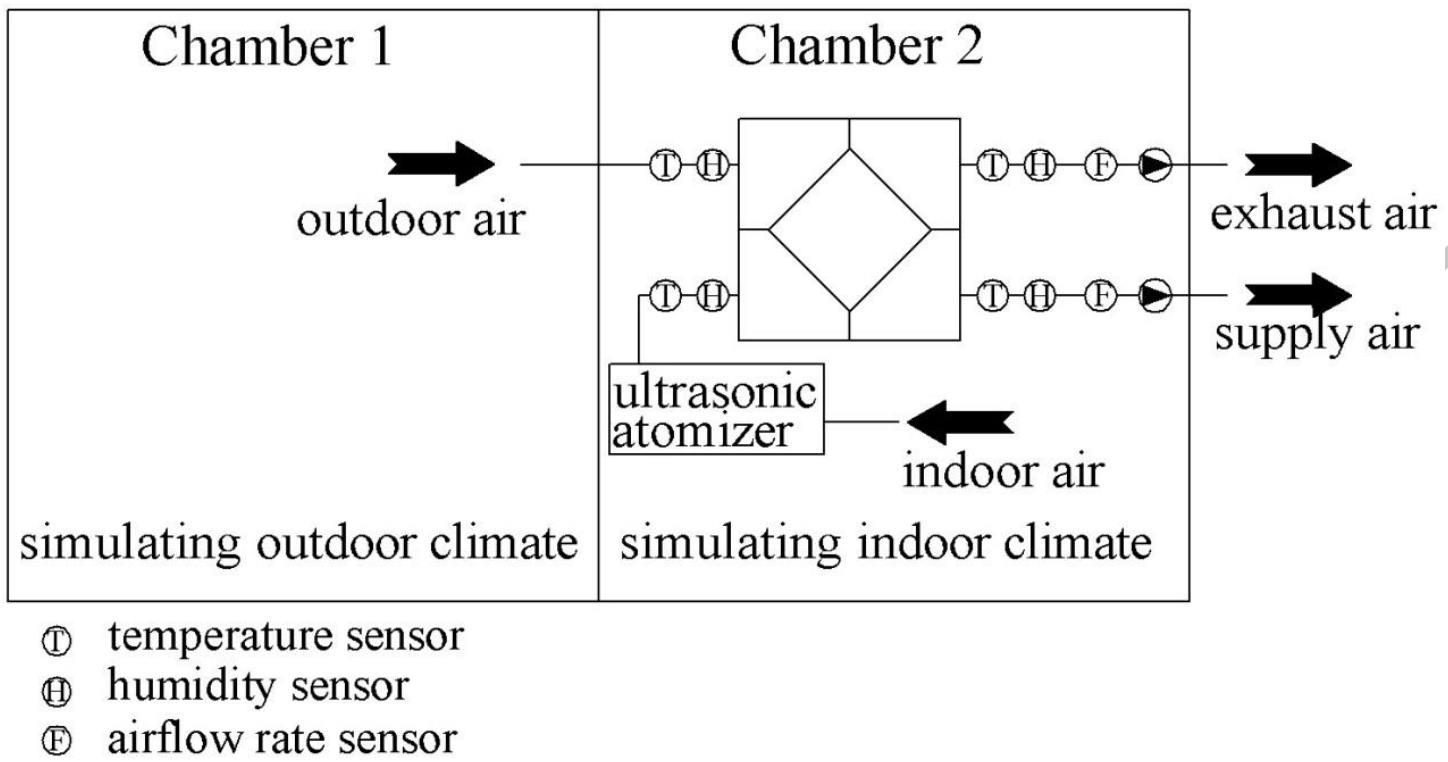

Figure 2. Schematic of the experimental setup for total heat recovery unit measurement

\section{Experiment design}

To investigate the impact of air temperatures, humidity ratios and airflow rates on the total heat recover efficiency of the proposed system, the experiment was designed with varied indoor and outdoor thermal climate conditions as well as varied airflow rates. The indoor thermal climate was designed to be with constant temperature as $25^{\circ} \mathrm{C}$, and three levels of relative humidity i.e. $35 \%, 50 \%$ and $65 \%$. The outdoor air was designed to be $35^{\circ} \mathrm{C}, 65 \% \mathrm{RH}$ and $38^{\circ} \mathrm{C}, 70 \% \mathrm{RH}$ which are the design and extreme hot and humid conditions for building ventilation in summer of Shanghai. The designed airflow rates were $15 \mathrm{~L} / \mathrm{s}, 20 \mathrm{~L} / \mathrm{s}$ and $25 \mathrm{~L} / \mathrm{s}$.

Table 1. Experimental cases of indoor, outdoor thermal climates and airflow rates

\begin{tabular}{cccc}
\hline $\begin{array}{c}\text { Experiment } \\
\text { case No. }\end{array}$ & $\begin{array}{c}\text { Indoor thermal } \\
\text { conditions }\end{array}$ & $\begin{array}{c}\text { Outdoor thermal } \\
\text { conditions }\end{array}$ & Airflow rates \\
\hline $1-\mathrm{A}$ & & & $15 \mathrm{~L} / \mathrm{s}$ \\
$1-\mathrm{B}$ & $25^{\circ} \mathrm{C}, 35 \% \mathrm{RH}$ & $35^{\circ} \mathrm{C}, 63 \% \mathrm{RH}$ & $20 \mathrm{~L} / \mathrm{s}$ \\
$1-\mathrm{C}$ & & & $25 \mathrm{~L} / \mathrm{s}$ \\
\hline 2-A & & & $15 \mathrm{~L} / \mathrm{s}$ \\
2-B & $25^{\circ} \mathrm{C}, 50 \% \mathrm{RH}$ & $35^{\circ} \mathrm{C}, 63 \% \mathrm{RH}$ & $20 \mathrm{~L} / \mathrm{s}$ \\
2-C & & & $25 \mathrm{~L} / \mathrm{s}$ \\
\hline $3-\mathrm{A}$ & & & $15 \mathrm{~L} / \mathrm{s}$ \\
$3-\mathrm{B}$ & $25^{\circ} \mathrm{C}, 65 \% \mathrm{RH}$ & $35^{\circ} \mathrm{C}, 63 \% \mathrm{RH}$ & $20 \mathrm{~L} / \mathrm{s}$ \\
3-C & & & $25 \mathrm{~L} / \mathrm{s}$ \\
\hline $4-\mathrm{A}$ & & & $15 \mathrm{~L} / \mathrm{s}$ \\
$4-\mathrm{B}$ & $25^{\circ} \mathrm{C}, 50 \% \mathrm{RH}$ & $38^{\circ} \mathrm{C}, 70 \% \mathrm{RH}$ & $20 \mathrm{~L} / \mathrm{s}$ \\
$4-\mathrm{C}$ & & & $25 \mathrm{~L} / \mathrm{s}$ \\
\hline
\end{tabular}

During the experiment, the temperatures and humidity ratios of the air at inlets and 
outlets of the total heat recovery unit were measured with Vaisala sensors (HMT130 three-wire transmitter). The sensors were all calibrated before the experiment and achieved an accuracy of $\pm 0.2^{\circ} \mathrm{C}$ and $\pm 2 \% \mathrm{RH}$.

\section{Data analyzing methods}

With the prototype unit and relative experimental setup, the temperature efficiency, humidity efficiency, enthalpy efficiency, proportions of sensible/latent cooling recovered and total heat transfer resistance of the proposed enthalpy recovery unit were measured and analyzed.

Based on the measured temperature and humidity ratio, the temperature and humidity recover efficiencies of the total heat recovery unit were calculated using the following equation 1 and equation 2 .

$\eta_{t_{i} c}=\left(t_{s}-t_{o}\right) /\left(t_{i}-t_{o}\right)$

$\eta_{X_{e} e}=\left(X_{s}-X_{o}\right) /\left(X_{i}-X_{o}\right)$

Where, $\eta_{t_{i} c}, \eta_{X_{s} c}$ are the temperature and humidity efficiencies of the enthalpy recovery unit. $t_{s}, t_{i}, t_{o}$ are the temperatures of supply air, indoor air and outdoor air, ${ }^{\circ} \mathrm{C} . X_{s}, X_{i}, X_{o}$ are the humidity ratios of supply air, indoor air and outdoor air, $\mathrm{g} / \mathrm{kg}$.

Using the following Equation 3, the enthalpies of the air upstream and downstream of the unit were calculated with measured air temperature and relative humidity.

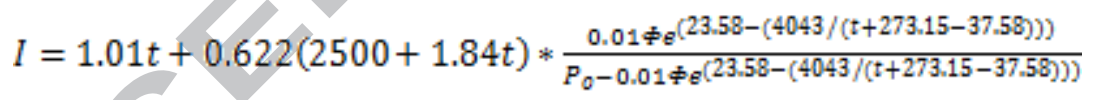

Where, $I$ is the enthalpy of the air, $\mathrm{kJ} / \mathrm{kg} . t$ is the air temperature, ${ }^{\circ} \mathrm{C} . \Phi$ is the relative humidity of the air, \%. $P_{o}$ is the barometric pressure of the air, $\mathrm{Pa}$.

The enthalpy recover efficiency of the proposed enthalpy recovery unit could be then calculated with equation 4 .

$\eta_{I_{0} c}=\left(I_{s}-I_{o}\right) /\left(I_{i}-I_{o}\right)$

Where, $\eta_{I_{a},}$ is the enthalpy efficiency of the proposed total heat recovery unit. $I_{s}, I_{i}$, $I_{o}$ are the enthalpies of the supply air, indoor air and outdoor air, $\mathrm{kJ} / \mathrm{kg}$.

The proportions of reduced sensible cooling load and reduced latent cooling load of outdoor supply air accounting for the total heat recovered is calculated with equation 
5 and equation 6 respectively.

$$
\begin{aligned}
& P_{s e}=\frac{\left(1.01 t_{0}+\left(1.84 t_{0}+2500\right) X_{0}\right)-\left(1.01 t_{s}+\left(1.84 t_{s}+2500\right) X_{0}\right)}{\left(I_{0}-I_{g}\right)} \\
& P_{l a}=\frac{\left(1.01 t_{s}+\left(1.84 t_{s}+2500\right) X_{0}\right)-\left(1.01 t_{s}+\left(1.84 t_{s}+2500\right) X_{g}\right)}{\left(I_{0}-I_{g}\right)}
\end{aligned}
$$

Where, $P_{s e}, P_{l a}$ are the proportions of reduced sensible, latent cooling load of outdoor supply air accounting for the total heat recovered respectively.

The thermal transfer resistance between the indoor exhaust air and the outdoor supply air could be calculated with equation 7 .

$R=\frac{2 \Delta t_{\log }}{p_{\text {air }}\left(I_{s}-I_{Q}\right)\left(Q_{\mathrm{i}}+Q_{Q}\right)} \times 10^{3}$

Where, $R$ is the total heat transfer resistance between the indoor exhaust air and outdoor supply air through the enthalpy recovery unit, ${ }^{\circ} \mathrm{C} / \mathrm{kW} . \rho_{\text {air }}$ is the density of the air, $\mathrm{kg} / \mathrm{m}^{3} . Q_{\hat{i}}, Q_{o}$ are the airflow rates of indoor exhaust air and outdoor supply air, $\mathrm{L} / \mathrm{s} . \Delta t_{\log }$ is logarithmic mean temperature difference of the indoor exhaust air and outdoor supply air, and it could be calculated with equation 8 .

$$
\Delta t_{\log }=\frac{\left(t_{0}-t_{e}\right)-\left(t_{g}-t_{i n}\right)}{\ln \left(\left(t_{0}-t_{B}\right) \operatorname{li}\left(t_{s}-t_{i h}\right)\right)}
$$

Where, $t_{e}, t_{i, k}$ are the temperatures of exhaust air expelled from the heat exchanger and the humidified indoor air entering the heat exchanger, ${ }^{\circ} \mathrm{C}$.

\section{Results}

During the experiment, the temperature and humidity in the climate chambers were controlled at the target values with maximum deviations of $\pm 1{ }^{\circ} \mathrm{C}$ and $\pm 5 \% \mathrm{RH}$ respectively. The airflow rates in the heat exchanger were controlled at the target values with maximum deviation of $\pm 1.5 \mathrm{~L} / \mathrm{s}$. The mean values of measured airflow rates, temperatures and relative humidity of the air at the inlets and outlets on both sides of the heat exchanger are shown in Table 2.

Table 2. Experimental measured indoor and outdoor airflow rates and thermal conditions

\begin{tabular}{ccccccc}
\hline Experimental & \multicolumn{2}{c}{ Airflow rates $(\mathrm{L} / \mathrm{s})$} & \multicolumn{2}{c}{ Temperature $\left({ }^{\circ} \mathrm{C}\right)$} & \multicolumn{2}{c}{ Relative Humidity } \\
\cline { 2 - 6 } Case No. & Outdoor air & Indoor air & Outdoor air & Indoor air & Outdoor air & Indoor air \\
\hline 1-A & 14.26 & 14.76 & 34.44 & 25.18 & $64.08 \%$ & $34.73 \%$
\end{tabular}




\begin{tabular}{ccccccc}
\hline \multirow{2}{*}{$\begin{array}{c}\text { Experimental } \\
\text { Case No. }\end{array}$} & \multicolumn{2}{c}{ Airflow rates $(\mathrm{L} / \mathrm{s})$} & \multicolumn{2}{c}{ Temperature $\left({ }^{\circ} \mathrm{C}\right)$} & \multicolumn{2}{c}{ Relative Humidity } \\
\cline { 2 - 7 } Outdoor air & Indoor air & Outdoor air & Indoor air & Outdoor air & Indoor air \\
\hline 1-B & 20.41 & 20.17 & 34.65 & 25.19 & $61.86 \%$ & $33.82 \%$ \\
1-C & 24.51 & 24.89 & 34.84 & 24.94 & $62.64 \%$ & $34.55 \%$ \\
\hline 2-A & 15.74 & 15.75 & 34.57 & 25.16 & $62.27 \%$ & $51.38 \%$ \\
2-B & 20.20 & 20.22 & 34.70 & 25.23 & $63.59 \%$ & $51.12 \%$ \\
2-C & 25.09 & 23.96 & 34.82 & 25.15 & $62.49 \%$ & $50.26 \%$ \\
\hline 3-A & 14.51 & 14.78 & 34.58 & 24.94 & $62.20 \%$ & $65.13 \%$ \\
3-B & 19.46 & 19.46 & 34.91 & 25.02 & $62.89 \%$ & $65.27 \%$ \\
3-C & 25.10 & 24.84 & 34.89 & 24.94 & $61.98 \%$ & $63.97 \%$ \\
\hline 4-A & 14.87 & 15.35 & 37.50 & 25.05 & $69.49 \%$ & $52.21 \%$ \\
4-B & 19.75 & 19.79 & 37.71 & 24.92 & $69.24 \%$ & $49.10 \%$ \\
4-C & 24.92 & 24.52 & 37.66 & 24.94 & $70.47 \%$ & $48.60 \%$ \\
\hline
\end{tabular}

\section{Heat recover efficiency}

The measured mean values of temperatures, humidity ratios and enthalpies of the outdoor air, supply air and indoor air are shown in Table 3. 
Table 3. Experimental measured indoor and outdoor airflow rates and thermal conditions

\begin{tabular}{|c|c|c|c|c|c|c|c|c|c|}
\hline \multirow{2}{*}{$\begin{array}{c}\text { Experimental } \\
\text { Case No. }\end{array}$} & \multicolumn{3}{|c|}{ Temperature $\left({ }^{\circ} \mathrm{C}\right)$} & \multicolumn{3}{|c|}{ Humidity Ratio $(\mathrm{g} / \mathrm{kg})$} & \multicolumn{3}{|c|}{ Enthalpy $(\mathrm{kJ} / \mathrm{kg})$} \\
\hline & $\begin{array}{c}\text { Outdoor } \\
\text { air }\end{array}$ & $\begin{array}{c}\text { Supply } \\
\text { air }\end{array}$ & $\begin{array}{l}\text { Indoor } \\
\text { air }\end{array}$ & $\begin{array}{l}\text { Outdoor } \\
\text { air }\end{array}$ & $\begin{array}{l}\text { Supply } \\
\text { air }\end{array}$ & $\begin{array}{c}\text { Indoor } \\
\text { air }\end{array}$ & $\begin{array}{c}\text { Outdoor } \\
\text { air }\end{array}$ & $\begin{array}{c}\text { Supply } \\
\text { air }\end{array}$ & $\begin{array}{c}\text { Indoor } \\
\text { air }\end{array}$ \\
\hline $1-\mathrm{A}$ & 34.44 & 20.95 & 25.18 & 22.91 & 15.65 & 6.93 & 93.52 & 60.89 & 43.09 \\
\hline $1-B$ & 34.65 & 20.87 & 25.19 & 22.25 & 15.58 & 6.75 & 92.04 & 60.62 & 42.62 \\
\hline $1-\mathrm{C}$ & 34.84 & 21.30 & 24.94 & 22.57 & 16.00 & 6.79 & 93.07 & 62.13 & 42.46 \\
\hline $2-\mathrm{A}$ & 34.57 & 22.04 & 25.16 & 22.27 & 16.77 & 10.28 & 92.01 & 64.87 & 51.59 \\
\hline $2-\mathrm{B}$ & 34.70 & 22.44 & 25.23 & 22.89 & 17.19 & 10.28 & 93.74 & 66.34 & 51.64 \\
\hline $2-\mathrm{C}$ & 34.82 & 22.53 & 25.15 & 22.55 & 17.28 & 10.05 & 92.99 & 66.66 & 50.99 \\
\hline $3-\mathrm{A}$ & 34.58 & 22.91 & 24.94 & 22.32 & 17.70 & 12.92 & 92.16 & 68.12 & 58.09 \\
\hline $3-B$ & 34.91 & 23.33 & 25.02 & 22.86 & 18.17 & 13.01 & 93.88 & 69.76 & 58.40 \\
\hline $3-\mathrm{C}$ & 34.89 & 23.20 & 24.94 & 22.50 & 18.02 & 12.69 & 92.93 & 69.25 & 57.50 \\
\hline 4-A & 37.50 & 23.92 & 25.05 & 29.77 & 18.84 & 10.39 & 114.34 & 72.09 & 51.75 \\
\hline 4-B & 37.71 & 24.01 & 24.92 & 29.81 & 18.95 & 9.68 & 114.67 & 72.46 & 49.82 \\
\hline 4-C & 37.66 & 24.71 & 24.94 & 30.32 & 19.79 & 9.59 & 115.93 & 75.33 & 49.61 \\
\hline
\end{tabular}

The temperature, humidity and enthalpy recover efficiencies were calculated and shown in the following Figure 3 - Figure 5.

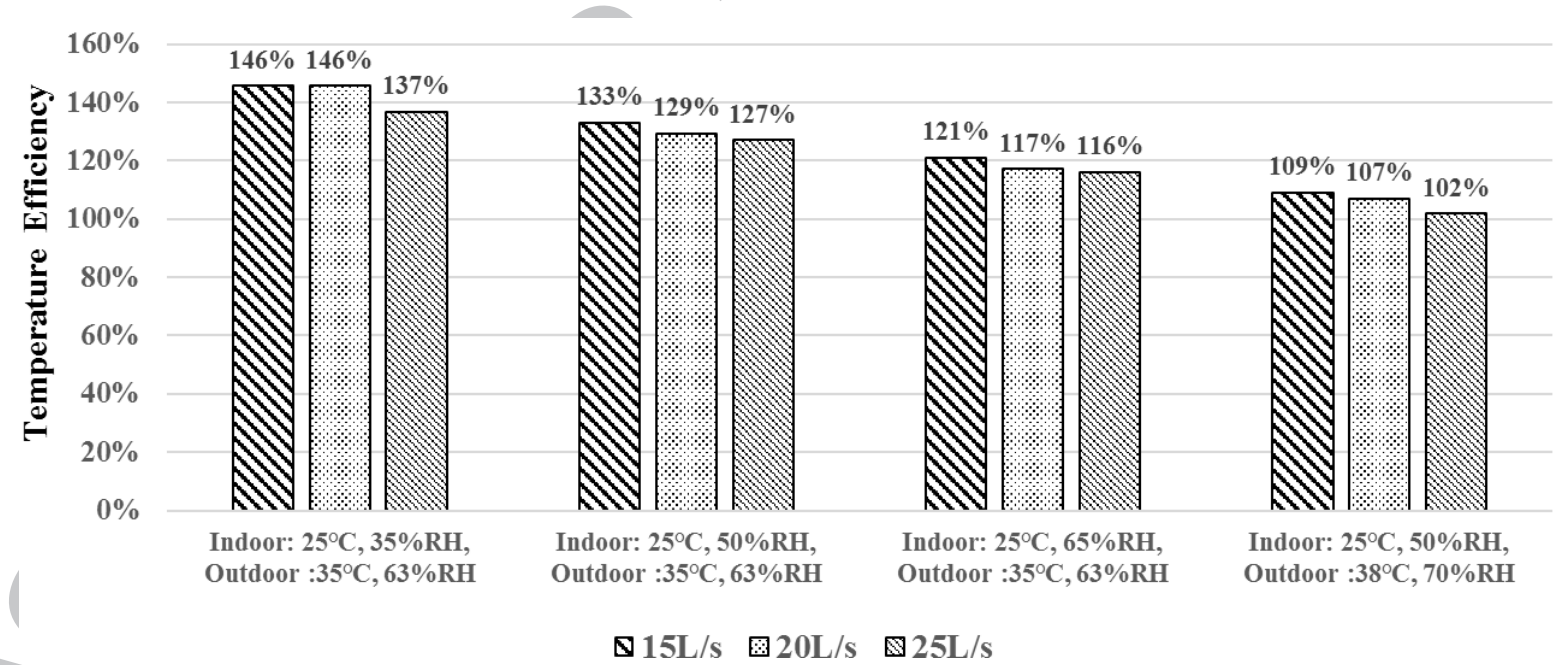

Figure 3. The temperature efficiencies of the proposed total heat recovery unit under different operation conditions.

Under the designed operation conditions, the temperature recover efficiencies were in the range from $102 \%$ to $146 \%$ which greatly enhanced the outdoor air cooling effect of the heat exchanger. The temperature recover efficiency was affected by air flow rates and air thermal conditions. Reducing airflow rate improved the temperature efficiency of the system due to increased heat exchanging area for per unit airflow. Lower indoor air humidity ratio led to higher temperature recover efficiency. This was because that the indirect flash evaporative heat exchanger used ultrasonic atomizer to humidify and cool the indoor air to its wet-bulb temperature, and indoor air with 
lower humidity ratio had a relative lower wet-bulb temperature which could enlarge the heat transfer driving force in the heat exchanger and led to a higher temperature recover efficiency. Outdoor air with higher temperature and humidity resulted in lower temperature recover efficiency. This was due to that when outdoor air was more hot and humid, more water condensation happened in the outdoor supply air channel of the heat exchanger, and the condensed water constituted an extra heat transfer resistance between indoor exhaust air and outdoor air supply.

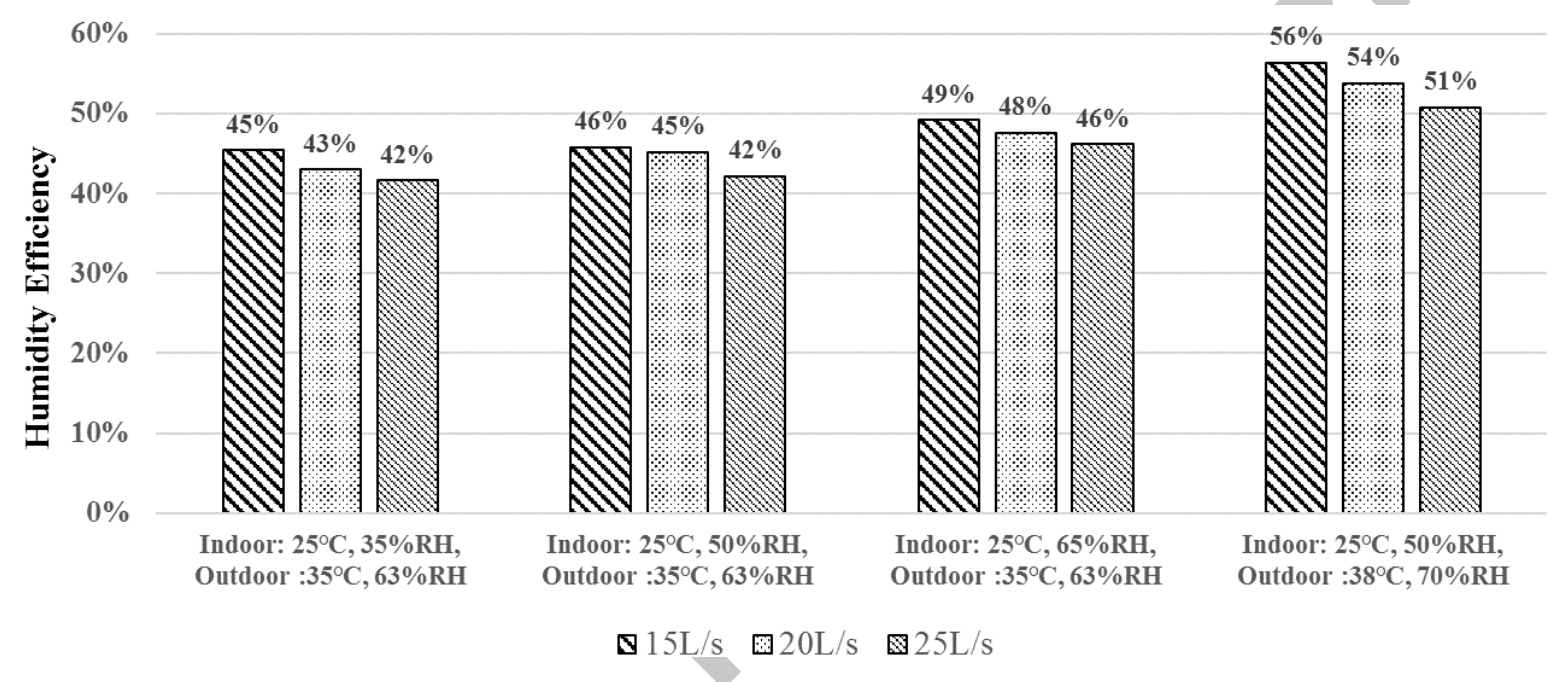

Figure 4. The humidity efficiencies of the proposed total heat recovery unit under different operation conditions.

Under the designed operation conditions, the humidity recover efficiencies were in the range from $42 \%$ to $56 \%$ which realized outdoor air dehumidification and enhanced total heat recover efficiency of the heat exchanger. The humidity recover efficiency was affected by air flow rates and air thermal conditions as well. Reducing airflow rate improved the humidity recover efficiency due to increased condensing area for per unit outdoor airflow. Lower indoor air humidity ratio could also lead to higher humidity efficiency due to its lower wet-bulb temperature which enlarge the moisture condensation driving force. The results also showed that in more hot and humid climates, higher humidity efficiency was achieved due to more water condensation happened in the outdoor supply air channel of the heat exchanger. 


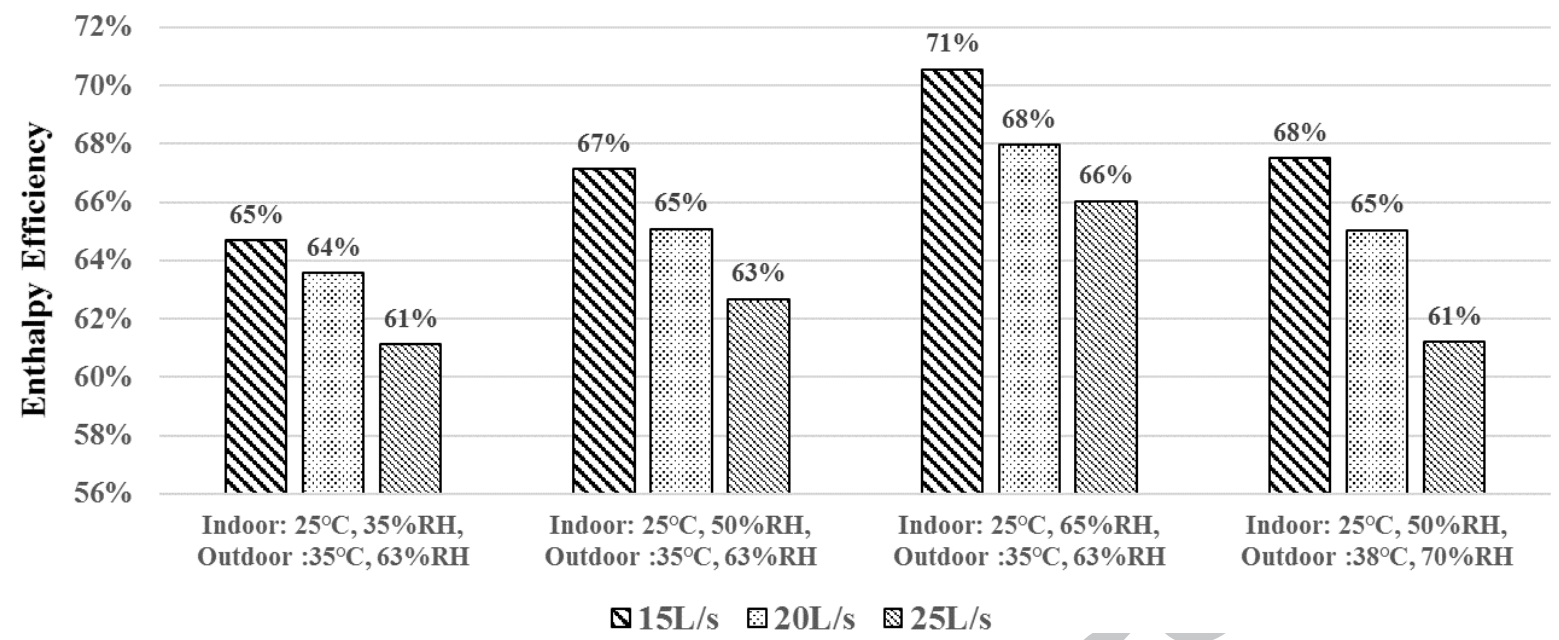

Figure 5. The enthalpy efficiencies of the proposed total heat recovery unit under different operation conditions.

Under the design operation conditions, the enthalpy recover efficiencies of the proposed indirect flash evaporative heat exchanger were in the range from $61 \%$ to $71 \%$ which could be comparable to that of rotary enthalpy exchanger or polymer membrane total heat exchanger. Similar with temperature and humidity recover efficiency, the enthalpy recover efficiency was affected by airflow rates and air thermal conditions. Reducing airflow rate improved the enthalpy recover efficiency due to increased temperature exchanging and moisture condensing area for per unit outdoor airflow. Lower indoor air humidity ratio could also lead to higher enthalpy efficiency due to its lower wet-bulb temperature which enlarged the sensible heat exchanging and moisture condensing driving force. Lower enthalpy recover efficiency was observed when outdoor air had higher temperature and humidity. As shown in Figure 3 and Figure 4, higher outdoor temperature and humidity resulted in higher humidity recover efficiency but lower temperature recover efficiency. When outdoor temperature and humidity became higher in the designed conditions, the decreas of sensible heat recovered is larger than the recovered latent heat increase which resulted in lower enthalpy recover efficiency.

\section{Proportions of the total heat recovered}

With the experiment results, the proportions of recovered sensible and latent heat accounting for the total heat recovering were analyzed and shown in following Figure 6. 


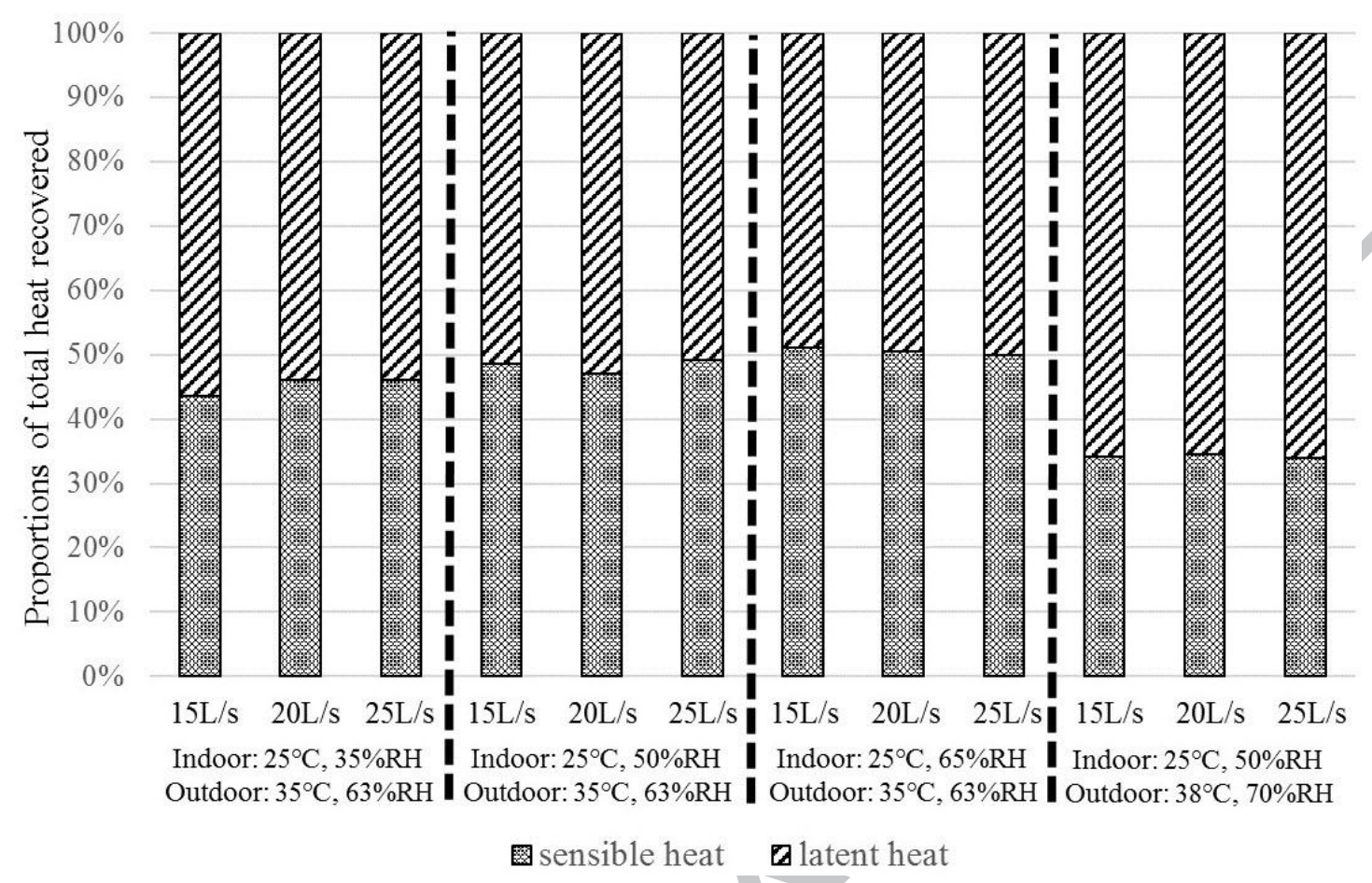

Figure 6. The proportions of heat recovered in the proposed enthalpy recovery unit under different operation conditions.

Under the designed operation conditions, the sensible cooling of outdoor air accounted for $34 \%-51 \%$ of the total heat recovered through the proposed system. The other $49 \%-66 \%$ of the total heat recovered was contributed by moisture condensing of outdoor supply air. The latent cooling (dehumidification) occupied a major part of the air thermal conditioning of outdoor supply air. Under the standard ${ }^{[22]}$ indoor thermal $^{2}$ condition $\left(25^{\circ} \mathrm{C}\right.$ and $\left.50 \% \mathrm{RH}\right)$ and design outdoor thermal climate for building ventilation in summer of Shanghai $\left(35^{\circ} \mathrm{C}\right.$ and $\left.63 \% \mathrm{RH}\right)$, the sensible cooling for outdoor supply air with the proposed system was in the range from $12.90 \mathrm{~kJ} / \mathrm{kg}$ to $13.17 \mathrm{~kJ} / \mathrm{kg}$ which accounted for $47 \%-49 \%$ of the total heat recovered. Under the extreme hot and humid outdoor thermal climate in summer of Shanghai $\left(38^{\circ} \mathrm{C}\right.$ and $70 \% \mathrm{RH})$ and standard indoor thermal conditions $\left(25^{\circ} \mathrm{C}\right.$ and $\left.50 \% \mathrm{RH}\right)$, the sensible cooling for outdoor supply air with the proposed system was in the range from $13.80 \mathrm{~kJ} / \mathrm{kg}$ to $14.58 \mathrm{~kJ} / \mathrm{kg}$ which accounted for $34 \%-35 \%$ of the total heat recovered.

\section{Thermal resistance of the total heat recovery unit}

The total heat recovery of the tested unit was based on evaporation of atomized water to cool indoor exhaust air to its wet-bulb temperature and make both sensible heat transfer and moisture condensation in the outdoor air channel. The total heat transfer resistance through the proposed IFEC heat exchanger was analyzed and shown in Figure 7. 


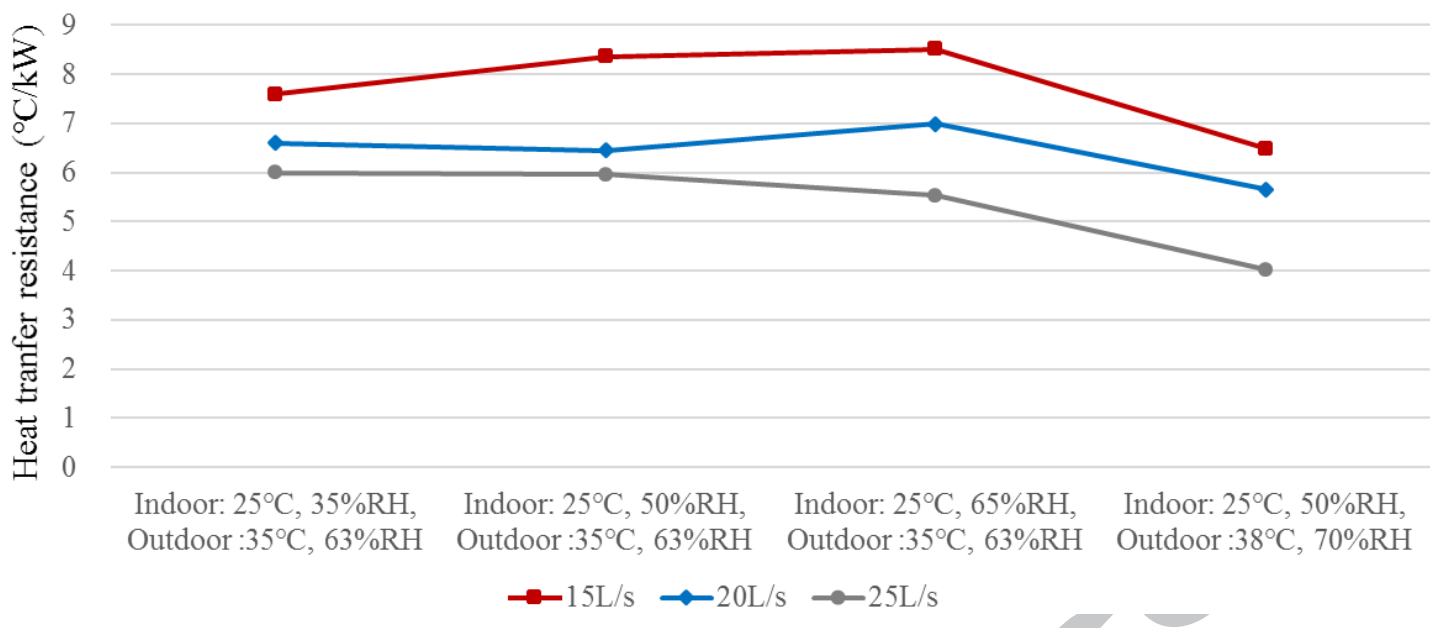

Figure 7. Thermal resistance of the proposed total heat recovery unit under different operation conditions.

The total heat transfer resistance of the proposed total heat recovery unit was in the range from $4.02^{\circ} \mathrm{C} / \mathrm{kW}$ to $8.51^{\circ} \mathrm{C} / \mathrm{kW}$. Increasing airflow rates weakened thermal resistance due to strengthened force convection heat transfer. However, the heat recover efficiency was decreased with increased airflow rates due to decreased heat transfer area for per unit airflow rate which have been shown in Figure 3- Figure 5.

\section{Discussion}

The experiment results showed that the enthalpy recover efficiency of the proposed system used in hot and humid climate was in the range of $61 \%-71 \%$. Compared to sensible heat exchanger, the total heat recover efficiency was greatly enhanced, and thus the cooling and dehumidification load for outdoor supply air could be largely reduced with the proposed system. Within the enthalpy efficiency, more than $50 \%$ of the total heat recovery was contributed by moisture condensation of the incoming outdoor air. The psychrometric heat recovery process under standard indoor thermal climate $\left(25^{\circ} \mathrm{C}, 50 \% \mathrm{RH}\right)$ and design outdoor thermal climate for building ventilation in summer of Shanghai $\left(35^{\circ} \mathrm{C}, 63 \% \mathrm{RH}\right)$ may be described in Figure 8 . Figure 8 also shows that the maximum energy that can be recovered by a sensory heat exchanger without the flash evaporative cooling is around 20\% theoretically. Assuming an $80 \%$ sensory heat recover efficiency, the real total heat recover efficiency by sensible heat exchanger could be only $16 \%$ in such hot and humid climate. The proposed indirect flash evaporative cooling heat exchanger enhanced enthalpy recover efficiency to $61 \%-71 \%$ and led to a significant energy saving for cooling and dehumidification of incoming outdoor air. 


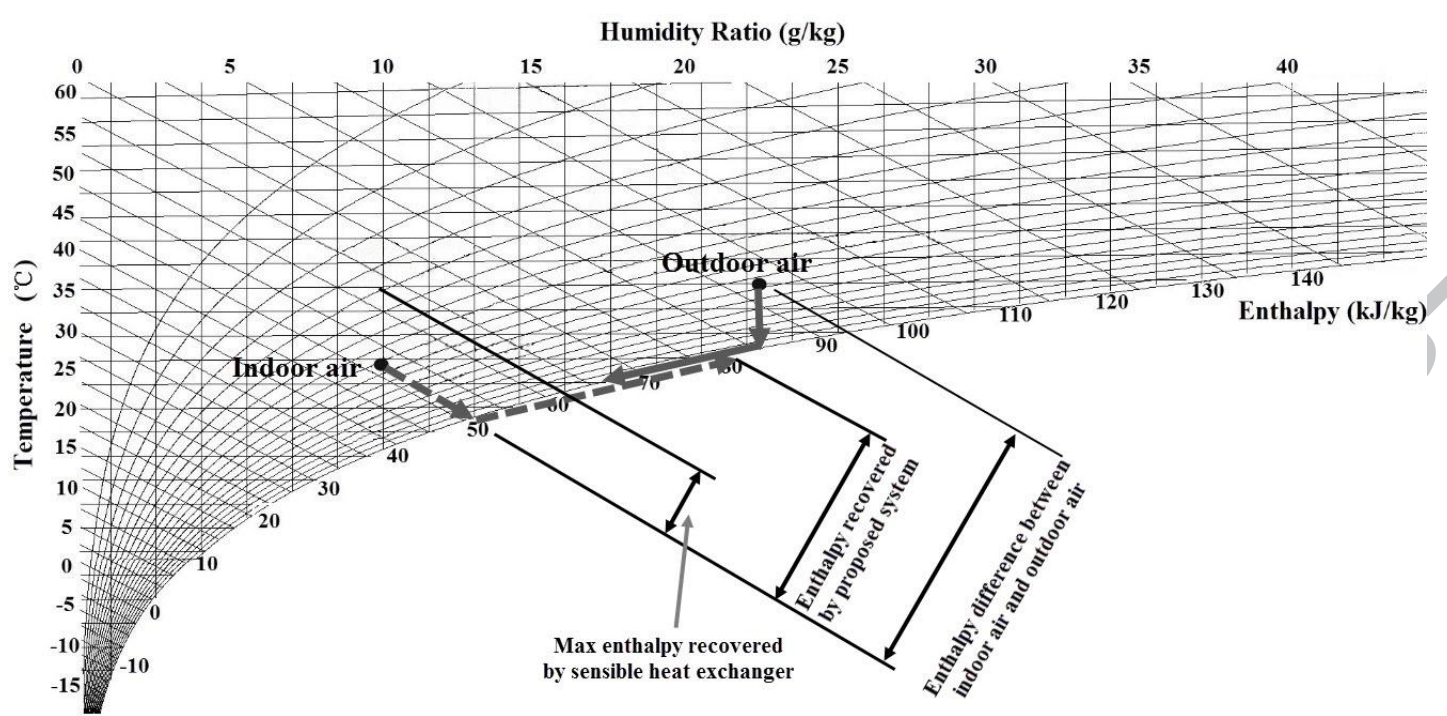

Figure 8. Psychrometric process of the proposed total heat recovery technology.

The enthalpy recover efficiency of the proposed system could be comparable to that of polymer membrane or rotary adsorption total heat recovery unit whose efficiency are from $50 \%$ to $75 \%$. The proposed total heat recovery unit was designed based on plate sensible heat exchanger combining with ultrasonic atomizer. The outdoor supply air was isolated from indoor exhaust air, and no contaminant permeation, carrying over or adsorption/desorption occurred in the proposed heat exchanger. Thus, the contaminant re-entrainment which have been demonstrated in polymer membrane and rotary adsorption heat recovery unit and constitute a severe pollution load in ventilation system were avoided in the proposed system. The ventilation efficiency could be then improved with the proposed IFEC enthalpy recovery unit.

Compared to conventional indirect evaporative cooling technology that use water drip packing or high-pressure spraying nozzles from which the water mists sizes vary from $3 \mu \mathrm{m}$ to $10 \mu \mathrm{m}$, the proposed IFEC utilized ultrasonic atomizer which produced water mist between $1-5 \mu \mathrm{m}$. The ultrafine mists increased water evaporation area and decreased heat transfer resistance between indoor exhaust air and outdoor supply air. Thus, the cooling effect could be enhanced through taking the flash evaporation potential of ultrafine mists.

The proposed total heat recovery technology required an atomizer accessory attached to a sensible heat exchanger, and humidified indoor exhaust air with mists. The concern might be the hardness of water. To avoid water scale forming in heat exchanger, softened water should be used in the atomizer. Although the flash evaporative cooling consumed some water, the condensed water from the incoming outdoor air was collected and reused for the evaporative cooling. Therefore, the net water consuming in this technology was little. All the recycled water was used in the exhaust air side of the heat exchanger and was isolated from being in contact with the incoming outdoor air for ventilation, which ensured that the technology was healthy and safe. Since the cooling of the exhaust air was due to water evaporation, no 
additional energy is required for this adiabatic cooling process.

\section{Conclusions}

A total heat recovery technology based on indirect flash evaporative cooling combing with plate heat exchanger was proposed. A prototype unit of the proposed system and relative experimental setup were developed, and experiment measurements were conducted to investigate the performance of the system under mimic hot and humid outdoor climates. Following conclusion are given based on the experiment results.

With the proposed total heat recovery unit, the temperature recover efficiencies could achieve $102 \%-146 \%$, and the latent heat recover efficiencies were in the range from $42 \%$ to $56 \%$.

The total heat recover efficiencies of the proposed indirect flash evaporative cooling heat exchanger were in the range from $61 \%$ to $71 \%$.

More than $50 \%$ of the total heat recovered was contributed by moisture condensation in the outdoor supply air.

The total heat transfer resistances of the proposed heat exchanger were in the range from $4.02^{\circ} \mathrm{C} / \mathrm{kW}$ to $8.51^{\circ} \mathrm{C} / \mathrm{kW}$ under the designed operation conditions.

Due to the high enthalpy recover efficiency which was comparable to that of polymer membrane or adsorption rotary heat exchanger and non-contaminant transfer property, the proposed indirect flash evaporative cooling total heat recovery technology could be a competitive choice for building ventilation.

\section{Acknowledgments}

This work was funded by the China Postdoctoral Science Foundation in the research project: "Theoretical and experimental research on a solid desiccant air-conditioning system which integrates the function of indoor air cleaning" (Project no. 2016M590036) and Bjarne Saxhofs Fond, Denmark in the project "Development of new total heat recovery ventilation technology for energy conservation in buildings".

\section{References}

[1] P. Wargocki, J. Sundell, W. Bischof, G.Brundrett, P.O. Fanger, F. Gyntelberg, S.O. Hanssen, P. Harrison, A. Pickering, O. Seppänen, P. Wouters. Ventilation 
and health in non-industrial indoor environments, Report from a European Multidisciplinary Scientific Consensus Meeting (EUROVEN). Indoor Air, 2002, 12(2): 113-128.

[2] D.P. Wyon, P. Wargocki. How indoor environment affects performance, ASHRAE Journal, 2013, 55(3): 46-52.

[3] N. Nashihara, P. Wargocki, S. Tanabe. Cerebral blood flow, fatigue, mental effort, and task performance in offices with two different pollution loads. Building and Environment, 2014, 71: 153-164.

[4] Z. Bakó-Biró, P. Wargocki, C.J. Weschler, P.O. Fanger. Effects of pollution from personal computers on perceived air quality, SBS symptoms and productivity in offices. Indoor Air, 2004, 14(3): 178-187.

[5] M. Orme. Energy Impact of Ventilation-Estimates for the Service and Residential Sectors. AIVC TN 49, AIVC, UK, 1998.

[6] K. Zhong, Y. Kang. Applicability of air-to-air heat recovery ventilators in China. Applied Thermal Engineering, 2009, 29:830-840.

[7] J. Nie, J. Yang, L. Fang, X. Kong. Experimental evaluation of enthalpy efficiency and gas-phase contaminant transfer in an enthalpy recovery unit with polymer membrane foils. Science and Technology for the Built Environment, 2015, 21(2): $150-159$.

[8] M. Rabbia, G. Dowse. Understanding energy wheels and energy recovery ventilation technology. Energy Recovery Ventilation. Carrier Corporation, 2000, Syracuse, New York.

[9] G.A. Khoury, S.N. Chang, D.A. Lessley, A.A. Abdelghani, A.C. Anderson. An investigation of re-entrainment of chemical fume hood exhaust air in a heat recovery unit. American Industrial Hygiene Association Journal, 1988, 49: 61-65.

[10]B. Anderson, K. Anderson, J. Sundell, P.A. Zingmark. Mass transfer of contaminants in rotary heat enthalpy exchangers. Indoor Air, 1993, 3: 143-148

[11]J.H Pejtersron. Sensory air pollution caused by rotary heat exchangers. Proceeding of Indoor Air, 1996, 3: 459-664, Indoor Air Conference, Nagoya, Japan. 
[12]C.A. Roulet, M.C. Pibiri, R. Knutti, R. Pfeiffer, A. Weber. Effect of chemical composition on VOC transfer through rotating heat exchangers. Energy and Buildings, 2002, 34(8): 799-807.

[13]E.L. Hult, H. Willem, M.H. Sherman. Formaldehyde transfer in residential energy recovery ventilators. Building and Environment, 2014, 75: 92-97.

[14]Y. Sheng, L. Fang, J. Nie. Experimental analysis of indoor air quality improvement achieved by using a Clean-Air Heat Pump (CAHP) air-cleaner in a ventilation system. Building and Environment, 2017, 122: 343-353.

[15] S.D. Antonellis, C.Maria. Joppolo, P. Liberati, S. Milani, F. Romano. Modeling and experimental study of an indirect evaporative cooler. Energy and Buildings, 2017, 142: 147-157.

[16]X. Cui, K.J. Chua, M.R. Islam, K.C. Ng. Performance evaluation of an indirect pre-cooling evaporative heat exchanger operating in hot and humid climate. Energy Conversion and Management, 2015, 12: 140-150.

[17]B. Porumb, M. Bălan, R. Porumb. Potential of indirect evaporative cooling to reduce the energy consumption in fresh air conditioning applications. Energy Procedia, 2016, 85: 433-441.

[18] S.D. Antonellis, C.M. Joppolo, P. Liberati, S. Milani, L. Molinaroli. Experimental analysis of a cross flow indirect evaporative cooling system. Energy and Buildings, 2016, 121: 130-138.

[19]H. Kim, S. Ham, D. Yoon, J. Jeong. Cooling performance measurement of two cross-flow indirect evaporative coolers in general and regenerative operation modes. Applied Energy, 2017, 195: 268-277.

[20] A. Tejero-gonzález, M. Andrés-chicote, E. Velasco-gómez, F.J. Rey-martínez. Influence of constructive parameters on the performance of two indirect evaporative cooler prototypes. Applied Thermal Engineering, 2013, 51:1017-1025.

[21]S. Moshari, G. Heidarinejad. Numerical study of regenerative evaporative coolers for sub-wet bulb cooling with cross-and counter-flow configuration. Applied Thermal Engineering, 2015, 89:669-683. 
[22] Ministry of Housing and Urban-Rural Development of the People's Republic of China. Design standard for energy efficiency of public buildings GB50189-2015. China Architecture \& Building Express, 2015, Beijing, China. 
Highlights

- An enthalpy recovery technology based on IFEC was proposed.

- The IFEC system combined ultrasonic atomizer with plate heat exchanger.

- A prototype unit of the IFEC enthalpy recovery technology was developed.

- Up to $71 \%$ of enthalpy recover efficiency could be achieved with the IFEC unit.

- More than $50 \%$ of enthalpy recovered was contributed by moisture condensation. 